\title{
Therapeutic itinerary and access to health services in cases of oral cancer deaths
}

\author{
Rodrigo Cesar Abreu de Aquino(1) \\ Maria Luiza Lopes Timóteo de Lima ${ }^{(1)}$ \\ Vanessa de Lima Silva(1) \\ Fábio Lima de Alencar(2) \\ Mirella Rodrigues ${ }^{(1)}$
}

(1) Universidade Federal de Pernambuco UFPE, Recife, Pernambuco, Brasil.

(2) Secretaria de Saúde do Recife. Recife, Pernambuco, Brasil.

This article is part of Rodrigo Cesar Abreu de Aquino's Master's degree dissertation of, defended in 2015, by the Graduate Program in Human Communication Health of the Federal University of Pernambuco.

Conflict of interests: Nonexistent

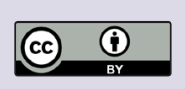

Received on: October 6, 2017

Approved on: August 23, 2018

Corresponding address:

Mirella Rodrigues

Rua Manoel de Arruda Câmara, 120, apto

904, Prado

CEP: 50720-140 - Recife, Pernambuco,

Brasil

E-mail: mirellarod@hotmail.com

\section{ABSTRACT}

Objective: to characterize the therapeutic itinerary followed by individuals who died from oral cancer in one area in the northeastern of Brazil, measuring the distances and average time spent in the searching for diagnosis and treatment service.

Methods: this is an epidemiological, cross-sectional, retrospective study, where the key informants were interviewed and the points of residence and services were geo-referenced. The variables related to the location of diagnosis, the distance traveled and the time spent for the diagnostic sites, treatment and place of death, services used during the therapeutic course and the main access difficulties were studied. Percent differences were tested using Fisher's exact test, with $\alpha=5 \%$. To evaluate the behavior and the identification of hot areas for this mortality, the Kernel density estimator technique was used.

Results: of the 18 cases of death due to oral cancer, $94.4 \%$ were diagnosed in reference centers; $83.3 \%$ were diagnosed and treated for up to 60 days; $77.8 \%$ were diagnosed and died in less than one year, and in $72.2 \%$, financials reasons were identified as an obstacle to access to a health care provider. The average distance traveled to the diagnoses sites was 7,364.7 meters, with an average time spent of 32.67 min and for treatment, it was 6,987.5 meters and 33.68 min.

Conclusion: the study showed that the diagnosis of the injury occurred predominantly outside the municipality of residence, although, people walked a fairly small distance to the health services, spending about half an hour for this displacement.

Keywords: Health Services Acessibility; Mouth Neoplasms; Health Care (Public Health) 


\section{INTRODUCTION}

Studies on the health care network highlight aspects related to the way and the moment when people seek access to health services in a timely and continuous manner, providing a link with the health professionals' team and, consequently, adherence to treatment proposed $^{1,2}$.

Health care networks are deliberate social responses to the health needs of the population and, as such, must operate in total consonance with the health situation of users. These systems are articulated through contextual factors (such as population aging, epidemiological transition and scientific and technological developments) and internal factors (such as organizational culture, resources, incentive systems, organizational structure and leadership style and management) ${ }^{3}$.

The path and all the movements made by these people or groups in the search for the maintenance or recovery of health is defined as a therapeutic itinerary, this care trajectory incorporates several resources of an organized health care network ${ }^{4,5}$.

The itinerary for the health services represents the way these systems work, in which their route includes all conventional relationships - medical consultations, hospitalizations, conducting preventive exams and diagnoses - with health services, as well as complementary therapeutic pathways - religious support, cognitive therapies and integrative and complementary practices. The choice of which path to follow is the result of the interaction of the behavior of the individual seeking care and of the professional who conducts it within the health system. There is still no consensus in the literature about the constraints to choosing this itinerary, but factors related to geographical and socioorganizational access to services directly influence this choice ${ }^{1,6-8}$.

Brazilian Unified Health System (SUS) considers primary care as one of the entry points for users, articulating their access to services at different levels of technological density, assuming the commitment of longitudinal monitoring within the care network?

The characteristics of services and health resources that facilitate or limit their use by potential users influence the use of these services offered ${ }^{1}$. Donabedian ${ }^{9}$ defines two dimensions of accessibility that are interrelated. The first is socio-organizational, which includes all the characteristics of service provision, which obstruct or increase the capacity of people to use these services, such as formal or informal policies that select patients according to their social and economic condition or diagnostic. The second dimension is geographic, which relates to the analysis of space that can be measured by linear distance, distance and time of locomotion, cost of travel and difficulties for mobility. The relationship of these with the use of services expresses the characteristics of the offer that intervenes in the relation between the individuals characteristics and the use of services.

Oral cancer is a term that includes several primary tumor sites, such as the lips and buccal cavity (buccal mucosa, gums, hard palate, tongue and floor of the mouth). The analysis of the incidence rates of oral cancer is more complete when all of its anatomical parts are evaluated together, as they are influenced by the same risk factors, and also because a lesion in a location of the mouth can extend to other parts of the $\mathrm{it}^{10}$.

Hence, facing a diagnosis of cancer requires each person to re-evaluate their own therapeutic itinerary, new interrelations and their own reflection upon existence, self-knowledge and self-development, which will enable the search for care, through trajectories, in the attempt to solve problems of the disease and as movements to preserve or recover health. It is a set of plans and actions that succeed each other, merge or overlap to deal with the illness ${ }^{5,11}$.

In Brazil, there are legal devices that deal with access and seek to ensure comprehensive care for the population, for the diagnosis and treatment of cancer, in a timely manner and in a structured and hierarchical way. Among them, the National Cancer Care Policy stands out, through Administrative Rule no. 2.439/ GM (minister gabinet) of December, 2005) and of the GM ordinance no. 741 of December 19, 2005. As far as the network is concerned, there are actions that go from the process of accreditation and management to the definition of different services and their skills and qualities.

Studies on access and itinerary are necessary, since there are few publications that address the path taken by cancer patients in search of diagnosis and treatment. Knowing this reality can contribute in a potential way with the identification of the main obstacles, which make access difficult for these patients.

Considering all that was exposed, this study aimed to describe the therapeutic itinerary covered by individuals who died of oral cancer in a city in the Northeast of Brazil, measuring the distances and average time spent searching for diagnostic and treatment services. 


\section{METHODS}

This paper was approved by the Research Ethics Committee of the Olinda Higher Education Foundation - FUNESO, under the CAAE number 21394913.9.0000.5194, opinion no 420.224, and all the key informants signed the Free and Informed Consent Term.

It is a transversal and retrospective epidemiological study, developed in Olinda, a city located in the Metropolitan Region of Recife, Brazil, with an estimated population of 397,268 inhabitants, predominantly urban, distributed in $43.5 \mathrm{~km}^{2}$ and 32 districts $^{12}$.

Olinda's health care network provides coverage of $50 \%$ of the population registered in the family health strategy and $23 \%$ is covered by the basic oral health teams. Olinda takes part in the planning, organization and evaluation of the actions of early detection of cancer within the scope of the Unified Health System (SUS), through inter-municipal agreement with Recife ${ }^{13}$.

In order to characterize the therapeutic itinerary, the cases of deaths due to oral cancer (CID C00 to C10) reported to the Mortality Information System (SIM) were identified in residents of Olinda, in the years of 2012 and 2013, with full assistance provided by SUS. Through the address records contained in the death certificates notified to SIM, interviews were conducted with the key informants of each case, through active residential search. These interviews were performed using the principles of the Verbal Autopsy (AV) protocol. $\mathrm{AV}$ is a questionnaire applied to the relatives and / or caregivers of the deceased person and used to obtain information about death in order to know the structure of mortality in these areas.The person who provides the information is the key to a successful investigation. In this case, a person of age who maintained direct contact with the case, must be responsible for the information provided ${ }^{14}$.

A route of visits was planned according to the location and proximity of the cases, which was made possible through the Google Maps ® version 2014 service, respecting their usage policies. The identification of the exact location of the residence was made by the researchers, with the support of the Family Health Team when the area was covered. After this stage, the research execution team, previously trained in the application of the collection instrument and the principles of the Verbal Autopsy protocol, started the data collection. When the site was closed, the visit occurred twice more, at different times and days, in order to guarantee the absence of residents in this place, as well as confirmation by questioning the lateral and frontal neighbors.

According to data reported to SIM, there were 38 cases of oral cancer deaths in the residents of Olinda. Of these, in six cases the address registered in the DO was non-existent or not located in Olinda; in three cases, the address did not correspond to the patient; for eight cases the place was closed or the residence had been sold, and the neighbors did not have the contact of the residents; there was one refusal to respond to the questionnaire; and we excluded two cases, after the application of the data collection instrument, due to the fact that the patients were not assisted by the SUS, totalizing 18 cases, which composed the population of this study (Figure 1).

The study variables are related to the location of diagnosis, the distance traveled and the time spent for the diagnosis and treatment sites and place of death, services used during the therapeutic course and the main access difficulties faced.

In order to measure the access to the services used, verifying quantity, distribution and distance between the residence and the services, the georeferencing technique of the cases was carried out using the Global Positioning System (GPS) to mark the points related to the residence and the services accessed. Garmin Etrex $10 \AA$ Portable GPS equipment was used, in which all points were marked in the interval between 2 p.m and 5 p.m, to avoid variation between the alignment of the satellites and decrease of the margin of error for their positioning ( $\leq 5$ meters) ${ }^{15}$.

A spatial distribution of the cases and services used for the diagnosis and treatment of oral cancer was performed. The Kernel density estimator was used to evaluate the behavior and identification of hot spots for mortality from this cause. The percentage differences of the categorical variables were tested using Fisher's exact test, with $a=5 \%$. For the variables time spent and distance traveled between the residence and the diagnostic and treatment services, measures of central tendency and dispersion were used. The software Epilnfo, version 3.5.4, Bioestat, version 5.0, were used, and for the spatial analyzes Arcview ${ }^{\circledR}$, version 3.2., And the Google Earth ${ }^{\circledR}$ tool were used. With this last one, it was possible to measure the distance and the time, considering the use of collective transport for the displacement. 


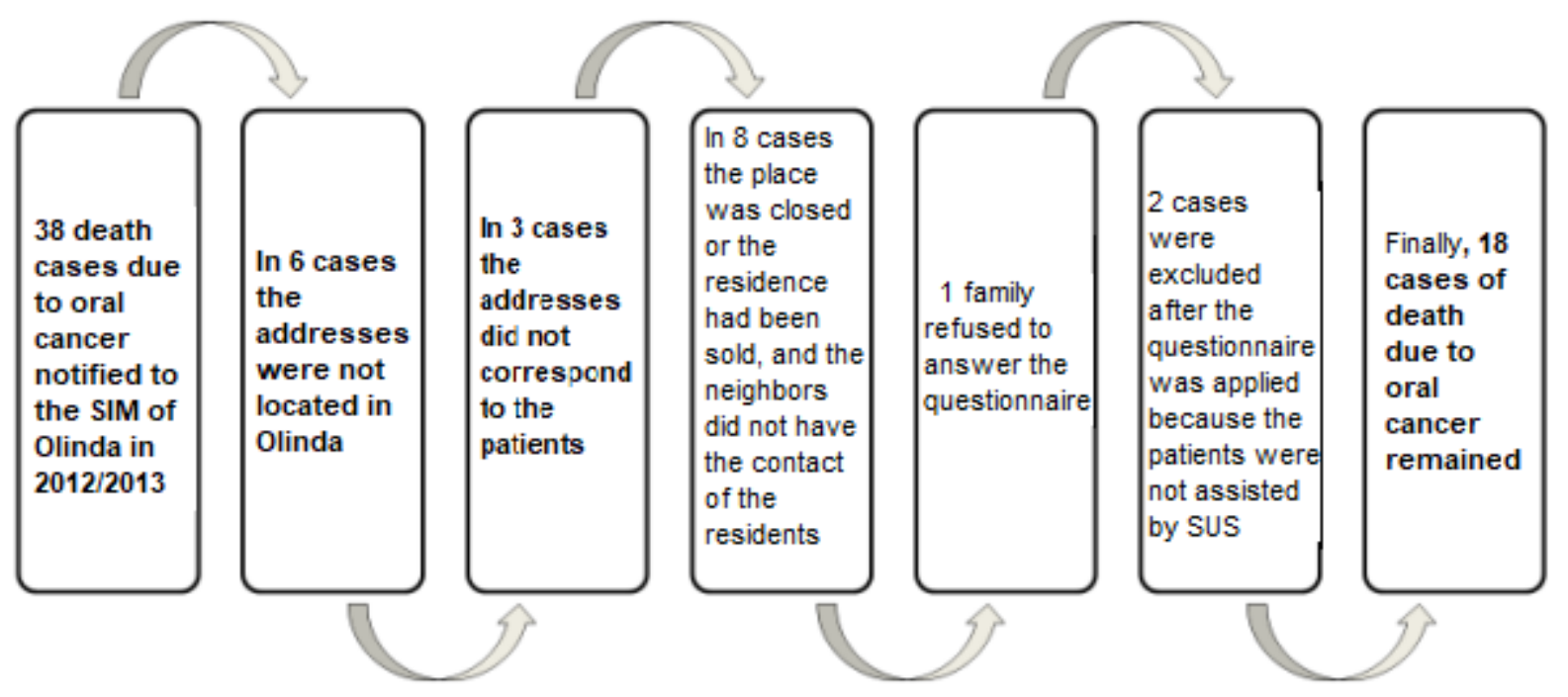

Figure 1. Flow chart for the study population after the losses

\section{RESULTS}

Of the 18 cases of death from oral cancer investigated, $94.4 \%$ (17) were diagnosed in specialized or referral services $(p<0.001)$. The time between diagnosis and treatment in up to 60 days occurred in $83.3 \%$ (15) of the cases ( $p<0.001, X=47.4$ days, $M d=30$ days, $\delta=29.9$ days $) ;(p<0.0001, X=22.7$ months, $M d=12$ months, $\delta=39.5$ months), the time between diagnosis and death was $77.8 \%$ (14). and in $72.2 \%$ (13) financial difficulties were identified as the main obstacles to access to services ( $p<0.001$ ) (Table 1).

The spatialisation of the deaths initially did not present any pattern of distribution, occurring in all territory of the Municipality of Olinda (Figure 2A).

Table 1. Access to cancer care for deaths from oral cancer, 2012/2013, Olinda, Pernambuco, Brazil

\begin{tabular}{|c|c|c|c|}
\hline Variables & $\mathbf{N}$ & $\%$ & p-value $\left.{ }^{*}\right)$ \\
\hline \multicolumn{4}{|l|}{ Diagnosis site } \\
\hline Basic health care & 1 & 5.6 & \multirow{2}{*}{$X^{2}=77.22 ; p<0.001$} \\
\hline Specialized service or Reference & 17 & 94.4 & \\
\hline \multicolumn{4}{|l|}{ Time between diagnosis and initiation of treatment } \\
\hline Up to 60 days & 15 & 83.3 & \multirow{2}{*}{$X^{2}=43.04 ; p<0.001$} \\
\hline 61 days or more & 3 & 16.7 & \\
\hline \multicolumn{4}{|l|}{ Time between diagnosis and death } \\
\hline Up to 12 months & 14 & 77.8 & \multirow{2}{*}{$X^{2}=29.76 ; p<0.001$} \\
\hline 13 months or more & 4 & 22.2 & \\
\hline \multicolumn{4}{|l|}{ Difficulties in accessing health centers } \\
\hline Temporal (Period between consultations and treatments) & 3 & 16.7 & \multirow{3}{*}{$X^{2}=79.13 ; p<0.001$} \\
\hline Geographical (distance and environmental conditions) & 2 & 11.1 & \\
\hline Financial (transport, lodging, food, complementary treatments) & 13 & 72.2 & \\
\hline Total & 18 & 100.00 & \\
\hline
\end{tabular}

Source: Data collected by researchers through verbal autopsy protocol

${ }^{\star}{ }^{\star}$ ) Fisher's exact test with $\alpha=5 \%$. 
(A)

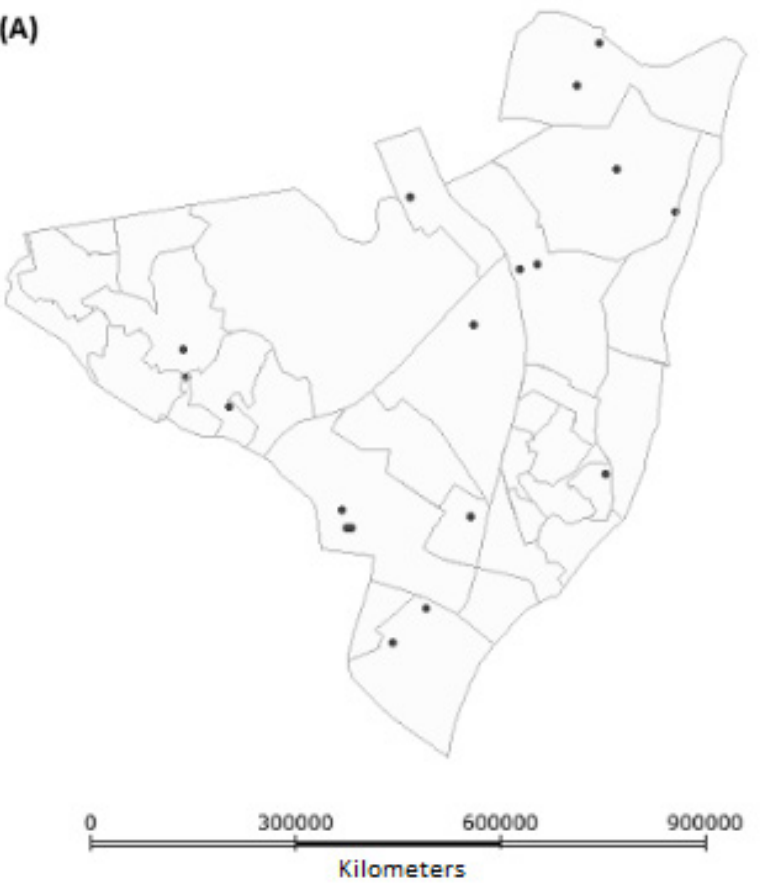

(B)

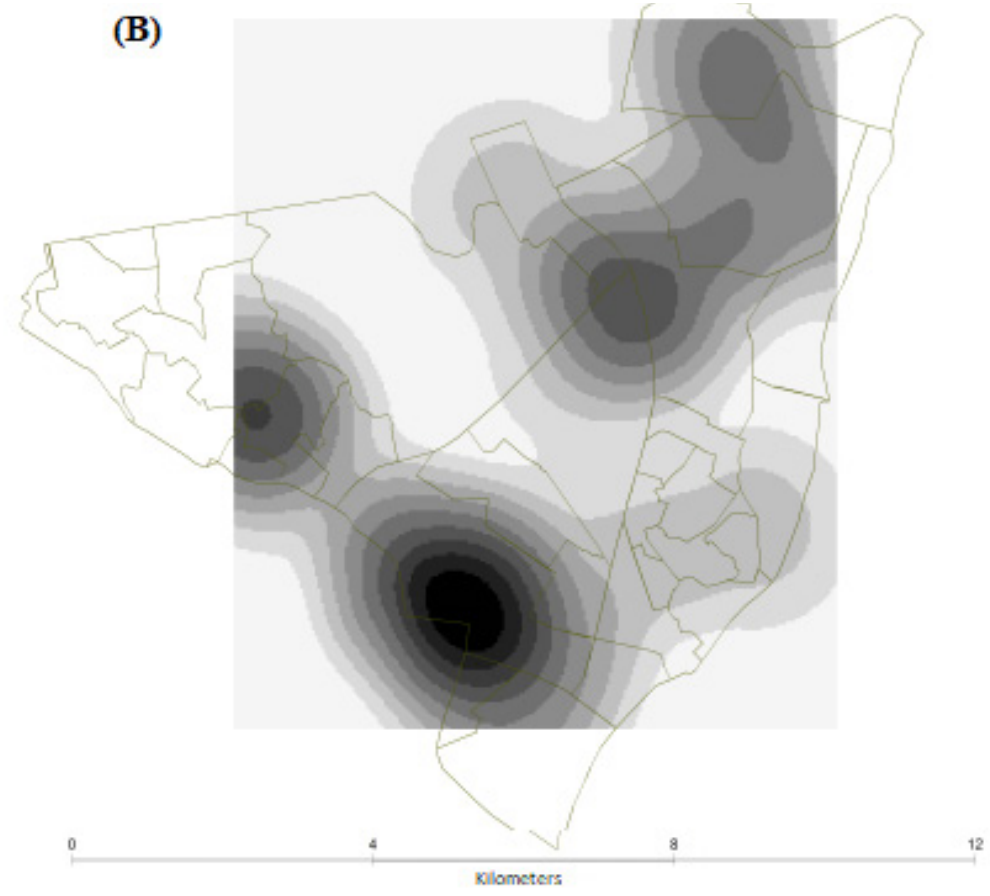

Source: Data collected by the researcher

Figure 2. (A) Distribution, (B) Spatial analysis by Kernel density estimator of deaths from oral cancer, Olinda-PE, 2012/2013

However, the Kernel density estimator pointed to the existence of a higher concentration of cases (hot area) for the occurrence of this event located more to the south of the municipality, in the border region with Recife (Figure 2B).

Concerning the services used for the diagnosis and treatment of oral cancer, $94 \%$ of the deaths were diagnosed outside the municipality of Olinda (Figure 3A and $\mathrm{B}$ ).
Taking into consideration the residences of the oral cancer deaths, the average distance traveled by these individuals to the diagnostic sites was 7.364 .7 meters $(\mathrm{Md}=6.300 \mathrm{~m}, \delta=3.567,38 \mathrm{~m})$, with an average time spent of 32, 67 minutes ( $M d=28 \mathrm{~min}, \delta=17.25 \mathrm{~min})$. At the treatment sites, the distance traveled was approximately 6,987.5 meters ( $\mathrm{Md}=6,950 \mathrm{~m}, \delta=2,974.98 \mathrm{~m})$, spending an average of 33.68 minutes until the service reported ( $M d=34.5 \mathrm{~min}, \delta=14.35 \mathrm{~min}$ ) (Table 2 ). 

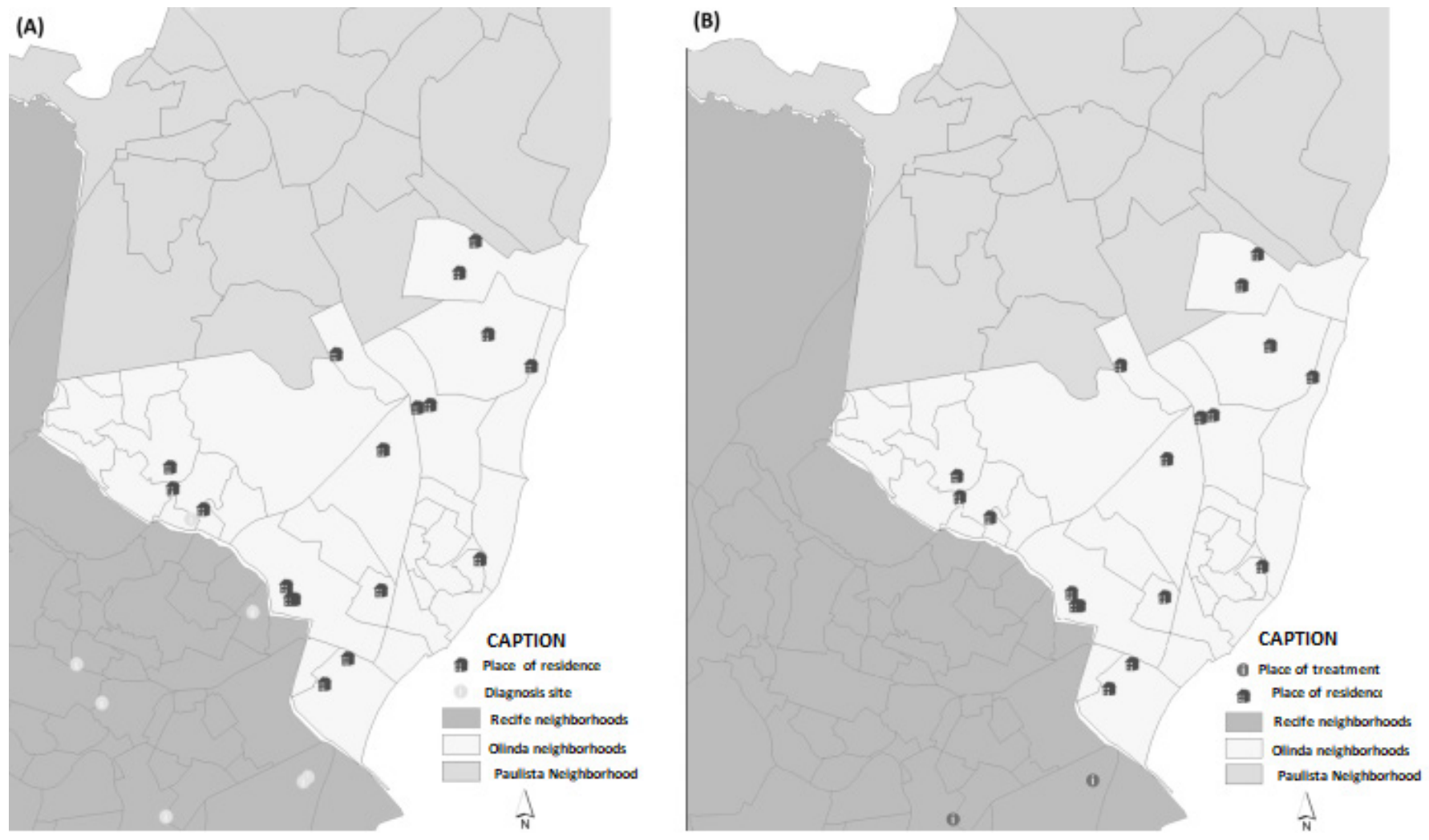

Source: Data collected by the researcher.

Figure 3. (A) Diagnosis site and (B) Place of treatment of the deaths from oral cancer, Olinda, Pernambuco, Brasil, 2012/2013.

Table 2. Access to oncological care of deaths due to oral cancer, 2012/2013, Olinda, Pernambuco, Brazil

\begin{tabular}{lccccc}
\hline Variables & Mean & Median & Minimum & Maximum & $\begin{array}{c}\text { Standard } \\
\text { deviation }\end{array}$ \\
\hline Residence to the local of Diagnosis & & & & & \\
$\quad$ Average Distance $\left(^{*}\right)$ & 7364.7 & 6300 & 2500 & 14200 & 3567.38 \\
$\quad$ Average Time $\left(^{* *}\right)$ & 32.67 & 28 & 11 & 60.25 & 17.25 \\
\hline Residence to the local of Treatment & & & & & \\
$\quad$ Average Distance $\left(^{*}\right)$ & 6987.5 & 6950 & 2500 & 12900 & 2974.98 \\
Average Time $\left(^{* *}\right)$ & 33.68 & 34.5 & 14 & 60 & 14.35 \\
\hline
\end{tabular}

Source: Data collected by researchers through verbal autopsy protocol

$\left(^{*}\right)$ Distance in meters using public transportation; $\left.{ }^{(*}\right)$ Time in minutes using public transport.

\section{DISCUSSION}

The results found in this study pointed out specialized and reference services as the predominant site for the diagnosis of oral cancer. This is due to the fact that the confirmation of the lesions needs procedures and inputs available only in medium or high complexity services. This demonstrates, to a certain extent, the fragility of early detection, after all, primary health care services act as a gateway to the health care network. However, there is difficulty identifying the earliest lesions that suggest neoplasia. Nonetheless, the use of health services is linked to the characteristics of the offer, the conduct of people in relation to morbidity and services and the staging of the disease $7,16,17$.

It was possible to verify that in most cases the waiting time between the diagnosis and the beginning of the specific treatment occurred within 60 days. This demonstrates that the health services begin the treatment within the time established by ministerial order number $1,220 / 14$. Because it is a pathology of rapid evolution, reaching the limit of this term may not 
be strategic to act on the progress of the disease. The Ministry of Health of Brazil establishes that the patient with malignant neoplasm has the right to undergo the first treatment in the SUS, within a period of up to 60 (sixty) days from the day on which the diagnosis is established in a pathological report or in a shorter term, according to the therapeutic need of the case recorded in a single medical record ${ }^{18}$.

The waiting time between the diagnosis and the beginning of treatment, as well as the itinerary covered by the individual in the different levels of the health services can generate anxieties and doubts about their clinical condition, difficulting the access to specialized service and, therefore, reduce the chances of effective treatment. In this scenario, Brazilian reality stands out; reality that despite the many efforts in the structuring effort, the cancer care network still deals with fragilities, with important time intervals between access to services at various stages of treatment ${ }^{19}$.

Depending on the waiting time for the start of treatment, as well as some difficulties to achieve it, such as distance, lack of financial resources and exacerbated side effects, the cure of the patient may be more time consuming than expected, or the patient can grow to a greater worsening of the disease. The results of this study describe that the majority of deaths occurred before one year (77.8\%). This may be related to the identification of the lesion in an advanced stage, due to a long period of time for the laboratory diagnosis of the lesion or the beginning of the therapy. An organized health care network, with well-defined flows and wellarticulated actions, can contribute to the correct orientation of the individual to the service he really needs, as well as reducing waiting times at all stages of his therapeutic path, leading to a good prognosis of the disease ${ }^{19}$.

A study carried out in Sydney, Australia, evaluated the patient's level of concern and the relation between the time elapsed between the diagnosis and the stages of the treatments performed, being that the patient is more distressed by the long waiting period between the diagnosis and the treatment, than with the complications of the therapy performed. The delay in the scheduling of specialized consultations is one of the access barriers for the integral care of the population, delaying the early diagnosis and, thus, a more effective treatment for the disease. In addition to this, the lack of defined criteria for the choice of the service of reference in which users will be forwarded is another aspect that makes access ${ }^{8,20}$.
Regarding the difficulties in accessing health services, financial resources, such as transportation and food costs, have been identified as the main impediment to their use of these services. In cancer care services, among some factors, the distance that the user goes through until entering the cancer care network and the costs involved for this displacement stand out. The distance traveled by the patient must be considered, as it will require repeated visits to the health services for specific care and treatment. In this sense, the location and decentralization of services, the time and costs involved with the displacement are fundamental for the evaluation of the accessibility standard of these individuals ${ }^{7,16}$.

The spatial location of the deaths showed a more homogeneous distribution in the territory of Olinda, however, with an area of greater density in the region near the border with Recife. It was observed in the Kernel analysis the existence of an area of greater occurrence for the most severe cases of oral cancer, which lead to death. These areas coincide with districts that present lower socioeconomic conditions, favoring an increase in risk factors for oral cancer, such as alcoholism, smoking and poor oral hygiene habits, as well as the relationship between this disease and the social determinants of health ${ }^{10}$.

It was identified that the diagnosis of the lesion occurred predominantly outside the municipality of Olinda. It was still possible to verify that all the patients started their treatment in reference hospitals in the neighboring city, Recife. This is partly because Olinda does not have high-complexity care with technological and therapeutic devices necessary for cancer care, participating only of the planning, organization and evaluation of early detection actions cancer under the Unified Health System - SUS, by means of an inter-municipal agreement with Recife $^{13}$. The concentration and centralization of diagnostic and therapeutic resources, desirable to guarantee higher volumes and better quality of care, often imposes extensive displacements on a considerable part of the population ${ }^{7}$.

The measurement of the distance traveled and the time spent by the patients to the diagnostic and treatment sites, using the collective vehicles as means of transportation, showed that the individuals cover, on avarage, fairly small stretches, although the standard deviations for both parameters have been high. However, this study neither evaluated the costs of this displacement, nor the amount of transportation used. The authors reaffirm the importance of investing in 
public policies aimed at transportation, for the access to health services is influenced by the distance and time to be traveled and by their cost for such displacement.

No studies were found that determine the ideal time and distance for the patient's access to health services. However, research indicates that the distance and time spent to carry out this course have relevance in the evolution of the disease and worsening of the condition, since the proximity of the health service interferes the early diagnosis and initiation of the treatment ${ }^{7,16}$.

It is assumed that the path traveled by users, from primary to specialized care, in search of diagnosis and treatment, is an indicator of the general quality of access to comprehensive care and the health system that provides this care ${ }^{20,21}$. The difficulties related to geographical accessibility and the time taken to reach specialized health services have been identified as a barrier to their use $\mathrm{e}^{22-25}$. In the study by Holmes et al. ${ }^{26}$ his association between the distance walked by the patient and the late diagnosis of the disease was evaluated. The displacement of the individual through his / her therapeutic itinerary causes the distance and delay to interfere directly in the search of the health service, as well as in adherence to the specialized therapy, reducing the early diagnosis and the possibilities of treatment.

Knowing the itinerary covered by the patient made it possible to identify the obstacles that may hinder the early diagnosis and interfere with the therapeutic process of the person with cancer, such as financial difficulties on the part of the family, ratifying the social determination of this health problem, and the fragility of basic health care in proceed to the diagnosis.

The time spent between diagnosis and death reinforces the importance of strengthening the network of cancer care, given that difficulties of this order can lead the individual to the diagnosis of the disease in advanced stages and considerably reduce the chances of cure.

Finally, some elements, such as inaccurate registration of addresses in the SIM, constituted methodological limitations to the study, making it difficult to locate the residences and the possibility of occurrence of memory bias of the key informants, in view of being a study retrospective. Nonetheless, contextualization strategies were adopted from the time of illness and death of the individuals, in order to reduce the effects of the temporal issue, providing greater security in the collection of information.

\section{CONCLUSION}

The therapeutic itinerary of the cases studied here showed that the diagnosis of the injury occurred predominantly outside the municipality of residence and that people traveled an average distance of seven kilometers to the places where they received health care, spending on average thirty minutes for this displacement .The main difficulties reported to access health services were financial, reaffirming the social determination of this health problem.

\section{REFERENCES}

1. Travassos C, Martins M. Uma revisão sobre os conceitos de acesso e utilização de serviços de saúde. Cad. Saúde Pública. 2004;20(Sup 2):S190-S198.

2. Cabral ALLV, Hemáez AM, Andrade ELG, Cherchiglia ML. Therapeutic itineraries: state of the art of scientific production in Brazil. Cien Saude Colet. 2011;16(11):4433-42.

3. Mendes EV. As redes de atenção à saúde. Organização Pan-Americana da Saúde Representação Brasil, 2011. [acesso em 2018 abr 30]. Disponível em: http://www. paho.org/bra/index.php?option =com docman\&view = download\&category slug $=$ servicos-saude-095\&alias $=1402$-as-redesatencao-a-saude-2a-edicao-2\&ltemid $=965$.

4. Brustolin A, Ferretti F. Therapeutic itinerary of elderly cancer survivors. Acta paul. enferm. 2017;30(1):47-59.

5. Pinho PA, Pereira PPG. Therapeutic itineraries: paths crossed in the search for care. Interface Comunic., Saude, Educ. 2012;16(41):435-47.

6. Instituto Nacional do Câncer. Ações de enfermagem para o controle do câncer: uma proposta de integração ensino-serviço. Instituto Nacional de Câncer. - 3. ed. atual. amp. - Rio de Janeiro: INCA; 2008.

7. Oliveira EXG, Melo ECP, Pinheiro RS, Noronha CP, Carvalho MS. Acesso à assistência oncológica: mapeamento dos fluxos origem-destino das internações e dos atendimentos ambulatoriais. $\mathrm{O}$ caso do câncer de mama. Cad. Saúde Pública. 2011;27(2):317-26.

8. Paul C, Carey M, Anderson A, Machenzie L, Sanson-Fisher R, Courtiney $R$ et al. Cancer patients' concerns regarding access to cancer care: perceived impact of waiting times along the 
diagnosis and treatment journey. Eur $\mathrm{J}$ Cancer Care. 2012;21(3):321-9.

9. Donabedian A. Aspects of medical care administration. Boston: Harvard University Press; 1973.

10. INCA. Instituto Nacional do Câncer. Coordenação de prevenção e vigilância. Estimativa 2014 Incidência de câncer no Brasil. Rio de Janeiro: INCA, 2014.

11. Rosa LM, Búrigo $T$, Radunz V. Itinerário terapêutico: alimentação e câncer. Rev. enferm. 2011;19(3):463-7.

12. Instituto Brasileiro de Geografia e Estatística (IBGE). Estimativas populacionais para o TCU em 2012. [acesso em 2014 abr 20]. Disponível em:http:// tabnet.datasus.gov.br/.

13. Secretaria de Saúde de Olinda. Sala de Situação de Olinda -2012. [Acesso em 2013 abr 18]. Disponível em: http://www.saudeolinda.blogspot.com.br.

14. Campos D, França E, Loschi RH, Souza MFM. Verbal autopsy for investigating deaths from ill-defined causes in Minas Gerais State, Brazil. Cad. Saúde Pública. 2010;26(6):1221-33.

15. Garrastazú MC. Manual de uso e orientação do GPS de navegação. Colombo: EMBRAPA, 2011. [acesso em 2015 jan 05]. Disponível em: http:// www.cnpf.embrapa.br/publica/seriedoc/edicoes/ Doc229.pdf.

16. Engel HR, Weiller TH, Farão EMD, Barros IFO, Bordignon JS, Luz EMF. Acessibilidade geográfica e organizacional: obstáculos entre usuários com tuberculose e os serviços de saúde. Rev Enferm UFSM. 2013;3(1):307-14.

17. Aquino RCA, Lima MLLT, Menezes CRCX, Rodrigues M. Epidemiologic aspects of mortality from oral cancer: understanding the risks to enable the early detection of changes in communication. Rev. CEFAC. 2015;17(4):1254-61.

18. Brasil. Casa Civil. Lei Federal № 12.732, de 22 de novembro de 2012. Disponível em: http://www. planalto.gov.br/ccivil_03/_ato2011-2014/2012/lei/ I12732.htm
19. Aquino RCA, Vilela MBR. Comunicação dos pacientes com câncer: Preocupação relacionada ao tempo de espera para o acesso e o itinerário terapêutico aos cuidados oncológicos. Distúrb. Comum. 2014;26(2):3-6.

20. Sousa FOS, Medeiros KR, Gurgel Junior $\mathrm{GD}$, Albuquerque PC. Do normativo à realidade do Sistema Único de Saúde: revelando barreiras de acesso na rede de cuidados assistenciais. Ciênc. saúde coletiva. 2014;19(4):1283-93.

21. Aquino RCA, Vilela MBR. Acesso e itinerário terapêutico dos pacientes com câncer: principais dificuldades enfrentadas para este percurso. Rev. Saúde. com. 2016;12(2):1-3.

22. Silva JES, Medina MG, Aquino R, Fonseca ACF, Vilasbôas ALQ. Acessibilidade geográfica à atenção primária à saúde em distrito sanitário do município de Salvador, Bahia. Rev. Bras. Saude Mater. Infant. 2010;10( Suppl 1):s49-s60.

23. Souza MSPL, Aquino R, Pereira SM, Costa MCN, Barreto ML, Natividade M. Fatores associados ao acesso geográfico aos serviços de saúde por pessoas com tuberculose em três capitais do Nordeste brasileiro. Cad. Saúde Pública. 2015;31(1):111-20.

24. Travassos C, Oliveira RXG, Viacava F. Desigualdades geográficas e sociais no acesso aos serviços de saúde no Brasil: 1998 e 2003. Ciênc. saúde coletiva. 2006;11(4):975-86.

25. Louvison MCP, Lebrão ML, Duarte YAO, Santos JLF, Malik AM, Almeida ES. Desigualdades no uso e acesso aos serviços de saúde entre idosos do município de São Paulo. Rev. Saúde Pública. 2008;42(4):733-40.

26. Holmes JA, Carpenter WR, Wu Y, Hendrix LH, Peacock $S$, Massing $M$ et al. Impact of distance to a urologist on early diagnosis of prostate cancer among black and white patients. J Urol. 2012;187(3):883-8. 